\title{
Cost Modelling Techniques for Availability Type Service Support Contracts: a Literature Review and Empirical Study
}

\author{
P. P. Datta, R. Roy \\ Decision Engineering Centre, Cranfield University, Cranfield, Bedford, MK43 OAL, UK \\ Partha.Datta@cranfield.ac.uk; r.roy@cranfield.ac.uk
}

\begin{abstract}
The research in this paper is focused on enhancing existing knowledge in cost estimation models at the bidding stage of service support contracts. The difficulty of this task lies in the long lasting contracts, which in some cases may reach even 40 years. The paper first reports the existing knowledge through detailed review of literature. The paper studies different service support contracts and reports the cost modelling techniques used in availability type contracts in the context of defence and aerospace industry. The contribution of this paper is to identify the key areas of improvement and business priorities in the area of cost modelling of availability type service support contracts.
\end{abstract}

\section{Keywords:}

Cost Modelling, Availability Type Service Contracts, Literature Review

\section{INTRODUCTION}

Upon entering into 21st century, the business environment for the manufacturing industry has changed significantly. Manufacturers now tend to include more services in their total offering to: facilitate the sale of their goods; lengthen customer relationships; create growth opportunities in matured markets; balance the effects of economic cycles with different cash-flows; and respond to integrated service solution demand [1-3]. A major shift in support and maintenance logistics for complex systems over the past few years has been observed in defence and aerospace industry. Availability contracting, a novel approach in this area, is replacing traditional service procurement practices. The premise behind availabilitycontracting is summarized in the official UK Ministry of Defence (MoD) guidelines (http://www.berr.gov.uk/files/file33168.pdf, 2007 ): "Contracting for Availability (CfA) is a commercial process which seeks to sustain a system or capability at an agreed level of readiness, over a period of time, by building a partnering arrangement between the MoD and Industry." Cost assessment of such service offerings remains a challenge and has not been addressed in literature. Some of whole life cycle cost literature focuses on assessing the maintenance or in-service costs [4-7]. But most of this literature is focused towards costing the service associated with stand-alone products. In most of these studies, services are viewed as "add-ons" to products and treated as mere features of the products. The literature on assessing the costs of availability type support service solution is rare.

This paper aims to bridge the gap. This research first studies the literature on different cost estimation techniques, whole life cycle costing, service and maintenance costing. Then it carries out an empirical study of cost assessment techniques used in availability contracts in service-based manufacturing organisations in the defence industry undergoing transition from being a manufacturer to a service provider. This research summarises the key best practices and areas for further improvement. The paper presents an integrated framework for costing service contracts using different modelling techniques and information for aiding the cost assessment of availability type service contracts.

\section{LITERATURE REVIEW}

A structured approach is adopted for the literature review. Studies were identified through an electronic search of the databases such as, Ingenta, Emerald, Science Direct, Engineering Village, Web of Science, IEEE Explore, library files and reference lists. In addition, the literature search was extended to the Internet, to NATO, NASA websites, as well as government (MoD, Department of Defense), academic institutions (MIT, Stanford, Georgia Tech) and large cost engineering companies' web pages for unpublished online information. Relevant literature is classified into several specific groups to set up inclusion, exclusion criteria. They are: whole life cycle costs, service and maintenance costs, cost estimation techniques. The literature review is reported below.

\subsection{Cost Estimation Techniques}

There are three well-recognized estimating models of cost [5]:

- the analogous method: compares costs according to similarities and differences with other projects (for parts geometrical characteristics influence), which has been applied a lot in the aerospace industry;

- the bottom-up method: collects all product cost values that are available, making it a highly data intensive method, activity based costing poses an example; and

- the parametric method: derives cost estimating relationships (CER's) and associated mathematical algorithms to reach cost estimates [8]. Models in this group include regression analysis, fuzzy logic, and neural networks [9]. The most often applied parametric estimation method is regression analysis [10]. These are known to be top-down applications.

At an advanced level, a range of methods such as feature based modelling, have also found application. This method uses relational drivers of cost, which means a direct relationship, is developed between the associated feature of a product and its cost [8]. Fuzzy logic is also a relatively new method, which applies highly sophisticated mathematical models to estimate costs, in situations where imprecision and uncertainty is very affective. This method has commonly been applied to represent vague 
and imprecise knowledge [8]. Harding et al [11] proposed that, within the construction industry, neural networks offered a useful route for cost estimation at the early stages. As the system receives new information it incorporates it into the decision making process [12].

\subsection{Whole Life Cycle Cost}

Whole life cycle cost (WLCC) of products comprise all costs attributable to a product from conception to those customers incur throughout the life of the product, including the costs of installation, operation, support, maintenance and disposal [13], [14]. There have been a number of proposed approaches to dealing with the WLCC over the years, presented in a review by Christensen et al [7] and majority of them are reported to be suffering from lack of available data. The use of historical maintenance data has been examined $[15,16]$ and it was found that historical information is most often combined within broader definitions that do not provide the transparency required for the development of accurate WLCC models. Parametric CER is a recognised technique for prediction of costs based on the known behaviours of past projects with similar key cost drivers $[17,18]$. However, lack of appropriate/available data is a huge obstacle in developing these relationships in the first instance. In order to avoid this, researchers [6] have used iterative approaches in which feedback is embedded into the practice. However, the main limitation of this linear model is, all the costing decisions are based on design level cost drivers alone. But within WLCC framework, the key drivers are not transparent within the developmental phase but extend through the operation/maintenance phases. Early et al [19] treated WLCC as an evolutionary process rather than a linear one and proposed a reverse spiral WLCC model. This model described a process by which a dynamic feedback model could be implemented in order to inform the WLCC, in which an integrated developer/operator modelling approach is adopted. The time-intensive nature of the process and the need for data transparency between developer-operator are the obvious disadvantages of such approach.

In construction and other capital intensive industries there is a further, more complex dimension that refers to longterm life cycle costs. Once cost modelling spans decades, instead of months or years, the issue is not only that of the availability and reliability of data, but also the compatibility of the timescale with the ever-shorter time horizons utilized by private and public corporations in their decision making processes, as well as the need to compare different economic and financial future scenarios [20]. Nicolini et al [20] showed through case study research in UK construction industry, the industry often operates without full understanding of costs throughout the supply chain, which changes with time. Nicolini et al. [20] found, most players in construction currently either develop prices through "top down" estimating based on rates for building elements or else can only price something once quotes have been received from the various subcontractors or materials suppliers involved in delivering a fixed design. The researchers thus found a gap in current WLCC research on to what extent or in which contexts the elemental costing can be replaced with "bottom up" estimation of actual labour, plant and materials costs throughout the supply chain.

WLCC is one of the most effective cost approaches in railway industry for prediction of total railway system costs. Jun and Kim [21] have showed the application of this technique in cost modelling of the brake module of a train vehicle. Several scenarios were created with reduced or increased man hour requirements. Several issues as uncertainty of input data, reality of the simulation models are also pointed out by the authors as issues with WLCC approach. Nilsson and Bertling [22] presented a WLCC analysis of wind power systems with possible maintenance management benefits in strategies using condition monitoring services. A present value method is applied to understand the present value impact of annual WLCC across the years of maintenance contract to understand the best maintenance strategy. Several scenarios are constructed to evaluate different maintenance strategies and their WLCC impacts.

The importance of WLCC for defence planning and military equipment has long been recognised [23, 24]. For most of the fighting equipment development work, there always exists a dominant proportion of operation and support cost compared with acquisition cost [25]. In defence context, it is clear that the detailed decisions on how the system is to be manned, supported and how it is to be repaired and overhauled (and the frequency of these tasks) will have a profound influence on the operating and support costs [26].

From the above literature review on WLCC, several issues and research gap have evolved. First, all studies in WLCC are focused on product and are mainly carried out at design stage with very little knowledge of maintenance or operation associated cost drivers and processes. Secondly, parametric methods are of use only when enough data is available on the product and its lifecycle activities. Accurate WLCC remains a time-consuming and expensive process. Thirdly, in long term WLCC studies, the ability to estimate when and to what extent the topdown costing can be replaced with "bottom up" estimation of actual labour, plant and materials costs throughout the supply chain remains a challenge. End-to-end cost estimation (starting from supplier to the customer) for long term WLCC remains a critical issue. Fourth, simulation models can be used in WLCC research, especially while considering maintenance/operations but validation of those models remains an issue. Finally, better data collection processes will enhance accuracy levels of WLCC. The role of existing knowledge (historical data or expert judgments) is evermore critical in this process. So, capturing and making proper use of this intangible asset remains an area for further research. Essentially, control of information and knowledge is an important part of this problem.

\subsection{Maintenance Costing}

The review of literature on costing of maintenance activities is carried out to understand the methods used to cost the maintenance activities. Jian and Hong-fu [27] tried to predict the maintenance cost for civil aeroplanes. They first identified the key factors contributing to the maintenance costs by detailed investigation of some Chinese airlines. Common characteristics of each airline are integrated and a general cost breakdown structure (CBS) of aeroplane maintenance is proposed. The final cost is added from the bottom up from this CBS and CERs are constructed to predict the maintenance costs. Bowman and Schmee [28] suggested a discrete event simulation model utilizing historical cost and failure data analysis results to evaluate contract price. The simulation discussed in the paper utilized the statistical failure and cost models to generate the simulated failure and cost models to generate the simulated failures and repair/replacement costs. Lamb [29] attempted to connect business performance and competitiveness to maintenance in the context of paper and pulp industry. He discussed the concept of availability as a measure of business performance and made reliability and 
maintenance operations as the key drivers for paper mill performance. Lamb approached maintenance costs from a totally different perspective, where the paper mill's maintenance budget is no longer an extrapolation of the past and rather it is a forecast of costs necessary to achieve the mill's planned business performance. Hence it can be found from the above limited number of studies that a combination of different cost estimation techniques (analogy-based methods, parametric techniques) in addition to simulation models are employed to cost maintenance offerings. Still the techniques used are data intensive and very much rely on historical data availability on maintenance.

\subsection{Service Costing}

Very few studies are reported in service costing. We are reporting here some of the different techniques used.

\section{Top down costing}

Top down costing first calculates the total costs of the service at the organisational, provider or departmental level, then disaggregates the total costs to the department or the units of services (or products) depending on the richness of available data and the homogeneity of services provided. It can be done through multiple steps, e.g. allocate costs to cost centres (e.g. support services workshop, project management), then divide the total costs of the cost centre by the number of units (e.g. spares supplied etc) [30, 31]. Top-down approach is less detailed and so accuracy can suffer. Furthermore, allocation of resources can be more or less arbitrary.

\section{Bottom-up costing/Activity based costing}

The bottom-up approach records resource utilisation at the individual service level, and aggregates service level utilisation data to identify the type of resources used and to measure resource utilisation in order to calculate the costs of specific services. It is particularly useful when cost data are not available from other reliable sources $[31,32]$. The disadvantages of this approach are the huge cost and long time required for costing complex services [31-33].

\section{Mixed Approach}

Mixed approaches are based partly on bottom up and partly on top-down approaches [34]. The mixed approach could avoid some of the disadvantages of both methods. A mixed method could be cheaper than using only bottom-up approach and it could be more accurate than using only top-down approach because it can reflect variation in resource consumptions. Top-down costing can be used where resource variation is reasonably small, and/or when the level of aggregation is relatively high, as well as where bottom-up costing would be very expensive and/or would not be worthwhile. On the other hand, bottom-up costing can be used where the precision/accuracy of resource measurement is important, and data collection is feasible in an economically sensible way. Study using mixed approach could suffer from the weaknesses of both methods. Local data may not be externally valid, whereas aggregate data may not be locally representative and could over or underestimate real resource utilisation [35].

\section{Target Costing}

Target costing was first introduced by Toyota in 1965 [36]. In a target-costing approach, the target profit is established and subtracted from the market driven cost (selling price) to determine target cost of services [37]. After target cost determination, the functional cost analyses are performed in order to reach the target cost.

\section{Analogy based estimates}

In some cases, when similar services or activities have already been valued and the unit costs calculated, information can be extracted from published reports or analysis. It may be helpful to contact the authors directly to discover more details about the costing exercise in order to assess the quality and reliability of these estimates [31]. However, published studies may suffer from weaknesses as good internal validity and poor external validity.

\section{Extrapolation based on expert opinion}

Although expert opinion is generally seen as the least reliable source of information about effectiveness and costs, several studies had to rely on multiple sources when assigning monetary value to resources, including expert opinion [38, 39]. Sometimes this helps where the experts are particularly experienced in the service delivery process.

\subsection{Summary}

The above study identified WLCC research used to cost maintenance and service functions across a spread of industry sectors. The best practice choice is guided by a number of criteria (a) the purpose of costing; (b) the type and complexity of the service; (c) the precision required; and (d) the data availability. From the above review it can be found that maintenance or in-service cost assessment studies in WLCC and maintenance costing literature are more focused towards costing the service associated with stand-alone products. In most of these studies, services are viewed as "add-ons" to products and treated as mere features of the products. They involve the provision of traditional reactive services, which focus on ensuring the proper functioning of the equipment consisting of maintenance, repair and overhaul, spares provisioning, technical publications and technical support [40]. The literature on integrated service support solutions is scarce and assessing the costs of integrated solution is rare. Literature on service costing is more limited to pure service type activities (health care, hospitality). In fact, no studies are found to address the cost estimation of service contracts at bidding stages in service based manufacturing sector, where the offering is in the form of a combination of product and services for a long period of time. Recently services in providing support to the client have grown from just maintenance or overhaul activities over the service life of equipment. This entails the alliance between support with client and supplier initiatives and advances client's processes, strategies and actions. Up to date, examples of such services involve supply and support chain management, integrated logistics support, asset management, equipment health monitoring and reliability trend analysis [40]. These types of services require closer relationships along the service supply chains. So now the definition of services is changing and very few of the WLCC research actually take an end-toend (customer to supplier) orientation focus in generating cost estimates. Most of the techniques stick on retrospective approaches (basing on past historical data) and do not relate to customer requirements for future.

\section{CASE STUDY}

In UK, the MoD in order to improve the through life management of defence equipment now contracts out based on availability. Under the concept of through-life management, the servicing and supply of spares takes second place to the overall goal of providing the availability and upgrades to mechanical and electrical equipment in one contract, building in potential equipment failures into the cost of the contract. Consequently, 
industry is incentivised to deliver reliable and capable equipment (e.g. an aircraft should be capable of flying day or night with the weaponry to defend and attack), reduce maintenance downtimes and minimise the number of required spares as part of a total package of maintenance, repair, overhaul, logistics support as well as equipment availability. Contracting for Availability (CFA) is the mechanism through which this level of support is made possible. In such cases, both the delivery and the availability of the service become part of the service offering. While organizations may be aware of the former and could price/contract accordingly, it is often a challenge to contract/price on the latter as availability is of value to the customer even if the actual service does not get consumed.

This paper studies the industry practice of life cycle costing of support service solutions across 5 such availability contracts between MoD and two organisations in defence industry. Among the 5 contracts, 3 are for defence platforms already in service phase, one is in manufacturing phase and one is entering into service phase. Unstructured interviews with cost estimators, contract managers and commercial officers are carried out to extract the best practices and issues around the cost assessment practice of such contracts.

\subsection{Inputs}

The various data, information inputs required for cost modelling are listed below in order of requirements.

\section{User Requirements}

All costing of service contracts are done based on user requirements. For example, if the user says he wants to fly 100 hours, all the services necessary to deliver that are listed. There is a fleet plan showing the number of aircrafts coming in and what services to do. Hence the user availability requirements actually give rise to service breakdown structure. One of the customer requirement documents is MDAL (master data assumptions list). For example, how many aircrafts the customer has got, how is he going to fly them, what rates he is going to fly them at, how many flying hours he has got against each type of aircraft etc are all included in the list. And the defence contractors are contracted against this list.

\section{User Top-level Budgets}

Almost all the projects needed to consider customer affordability issues, their top-level budgets.

\section{Service Breakdown Structure (SBS)}

According to a suitably determined service breakdown structure from 3.1.1 above, data related to the operation and maintenance activities of the system to be maintained needs to be collected. This breakdown structure

\section{Historical data \& Expert opinions}

Supply support team for one of the contracts looked at every single repairable item by pulling the history on it. They looked at historical price variance and usages to estimate variance of potential demand. Purchases, average prices, number of transactions in the past act as source of data. A new equipment service contract with no history of service breakdown structure is established by speaking to a number of subject matter experts (SME). Even SME helped develop CERs for parametric modelling of costs. In contracts where past historical data is available, understanding manpower requirements for previous maintenance schedules are used to estimate the time required for doing a maintenance job in current system.

\section{Supplier Inputs}

In these contracts, as the industry are managing spares, they have to maintain procurement setups and have contracts in place with suppliers for annual supply of certain number of parts needed to meet the flying hours stated in MDAL. So supplier prices for these supplies are required to cost service activities under each availability contract.

\subsection{Techniques}

Using industry standards/catalogues, Expert Judgments

For finding the mean time between failures (MTBF), the industry and its suppliers use industry standard data. One of the organisations relied on design expert experience in costing obsolescence. Historical data is not useful for costing obsolescence. Generally there is a commercial standard for estimating obsolescence which depends on equipment costs. Most organisations use engineering judgment to go for planned obsolescence cost assessment.

\section{Bottom up costing}

Three of the contracts studied are mainly based on manpower and employs bottom up approach for cost assessment. Once the profiling of activities carried out in repair and support is done, the profiling of labour and maintenance is carried out accordingly and thus requires use of bottom-up costing.

\section{Modelling What-if Scenarios}

Multiple what-if scenarios (based on usage, for example, hours of flying or days at sea) are run by the contract costing teams to understand spares costing for supporting equipment through its lifetime. The spares provisioning, fixed and variable support costs are summed to give an overall cost profile that has direct relation with availability. These costs are optimised to achieve an optimised operational availability within a budget constraint.

\section{Top-Down and Bottom Up}

One organisation used a combination of both top-down and bottom-up cost modelling technique to arrive at the estimates. MoD's top level budget and the bottom up costs are compared and problems in terms of driving down costs are identified and costed upon.

\section{End to end estimating}

Four contracts from one organisation use end-to-end estimating process before bidding for a contract. It uses the method of estimation after visualising the point of contract the service is in and where the organisation is in terms of the contracting process. For example, if the organisation realizes an opportunity but has not decided to bid, it uses a rough estimate based on the price of similar equipment service activities along with some riskadjustment. When the company decides to bid, the estimator goes through the company processes of life cycle management and adopts a more thorough approach needing better Statement of work, better drawings, plans and involvement of suppliers.

\section{Top down Parametric Estimates}

In many projects top down estimates are used where enough data is not available. For example in one of the service contracts, the industry's bid team employed a top down cost estimation process by constructing a SBS first and identifying 10-20. Budgetary estimates are formed based on levels of services required by MoD. Thus "As-Is" costs are established after spending 6-12 months understanding MoD's service process, cost drivers. Then the industry as design authority finds ways to reduce those costs. This gives the to-be costs. Range of possible 
savings against As-ls are identified - supply chain, fleet management, optimising capability required in aircraft, managing obsolescence, improving maintenance throughput, reducing levels of risings/faults, reducing nofaults-found, improved testing facilities of aircrafts, reducing spares in supply chain repair loop. In order to minimise costs, one organisation cut off support activities as early as possible in the service life of the equipment by creating a stock buffer. Another key feature is to make maximum use of all equipment drawn down from service to minimise obsolescence, calibration and maintenance costs.

\section{Analogy based estimates}

In estimating maintenance costs of new destroyer ship, parametric estimating in an equivalent ship is used. Then based on how bigger the new ship is the estimators came up with a multiplying factor for the time of maintenance tasks. Similarly analogy is used for all maintenance activities for all other contracts.

\section{Joint Cost Model}

The estimates for one contract are produced by speaking with SMEs in MoD and company on activities, manpower taken, CER, levers and drivers between cost models (MTBF, turnaround times, and repair rate). SMEs populated CERs from their equipment, for Monte Carlo and probabilistic modelling put ranges to the estimates.
Risks in risk register are populated by joint risk reviews. This has helped as they had to set cost targets based on affordability and availability. So getting $M o D$ and suppliers around the table helps to understand the cost constraints, understanding the kind of support solutions needed to meet them and how flexible they need to be.

On analysing the different cost estimation techniques used across different availability type contracts it is found that analogy based techniques, use of historical data and expert opinions are the most popular techniques. Projects at the start of bidding normally tend to use more top-down process of estimating when reliable data is not available. Most contracts used prior experience, huge historical data to do bottom up estimating before submitting the bid. Only one contract compared with the top down estimates to fit affordability requirements set by customer. Others used bottom up estimating to study and improve the As-Is costs of customer. At the same time, interviewees suggested use of analogy based estimates for costing new equipment that has not been in service before. Analogy based estimates are also used in cases where data is available on similar equipment services. Though what-if models are used to study the spares provisioning, spares optimisation is carried out only in one case. Almost all the interviewees use catalogues to base their estimates of material prices.

\subsection{The generic Process}

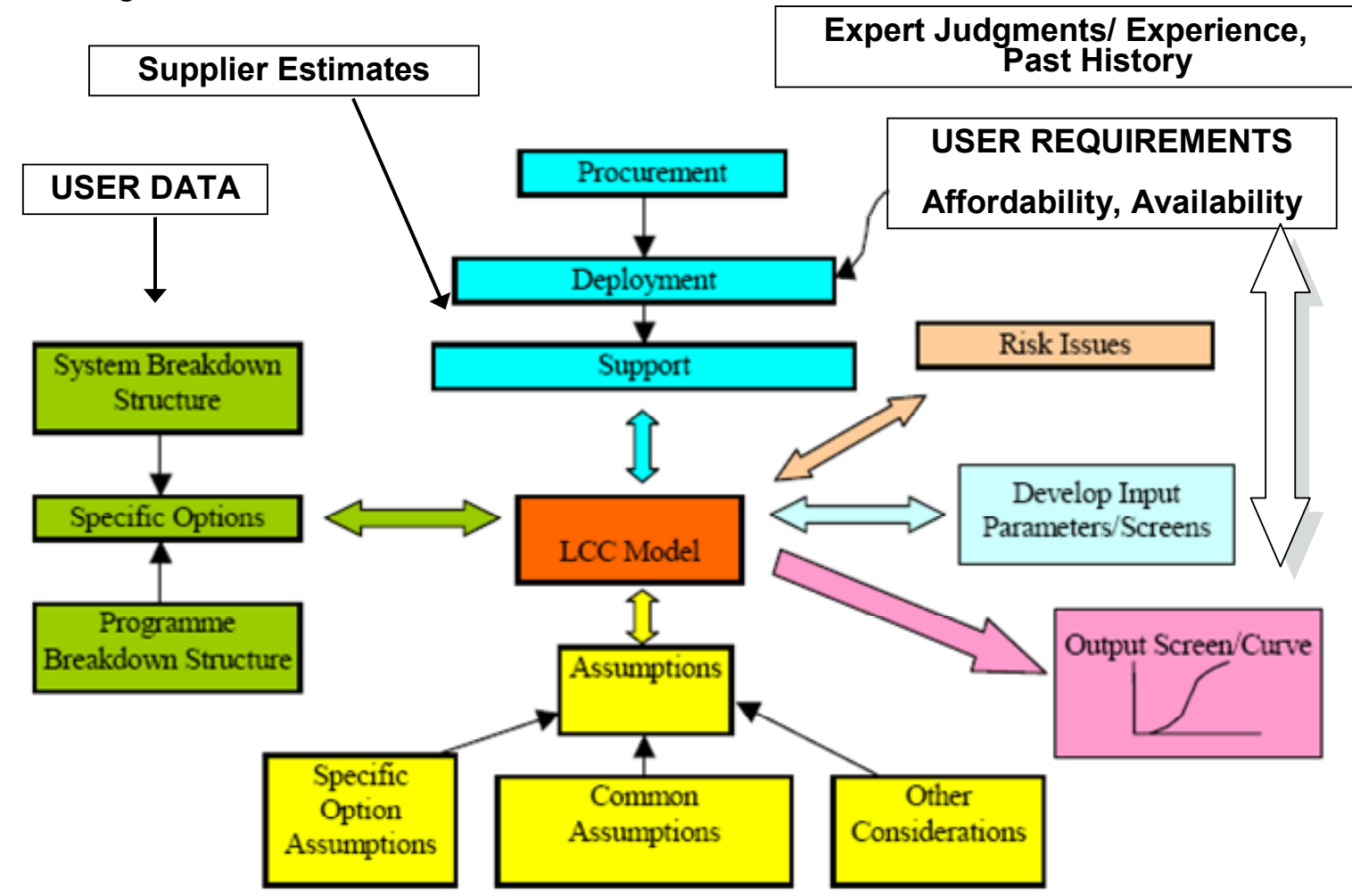

Figure 1: Life cycle costing framework for Availability Type Contracts

Based on the above findings from industry practices and data inputs in cost estimation of availability type service contracts, a generic framework is constructed and shown in Figure 1. The figure represents the components of the cost estimation process. The framework in the figure is broken down into a number of areas. On the left (in green) is the SBS reflecting the system, any specific options relating to the system and details of the programme timescale. This is derived from user data originating from user provided details of the activities. The inputs to the modelling framework are represented in white boxes. On the top is the programme documentation relating to procurement strategy, how the system will be deployed in operational and peacetime use and how it will be supported in these environments. The inputs from suppliers and users would support the understanding of the proposed deployment. At the bottom are the ground rules and assumptions (MDAL). These are recorded in a document and the information would be used to populate the areas of the model where no hard data was available. This forms the basis of equipment service at initial stages. On the right hand side, the risk issues could be included 
within the model so as to obtain a 'risk adjusted' cost. These risks are mainly process risks generated by talking to experts and experienced people focusing mainly on the service process risks from industry's point of view. The whole framework depends on expert judgments, past historical figures from similar equipment. To avoid an over complicated implementation it may be necessary to develop some suitable input and output screens to assist the user to find costs for different variations of the input parameters and carry out "what-if" type simulations. It is essential that all life cycle cost models are robustly tested and validated to ensure the correct operation of the equations in relation to the input attributes. And for this multiple iterations to match with user requirements and SME judgments are needed to validate and verify the whole framework.

So from Figure 1 and the above practices discussed for various availability type contracts it can be summarised that, there are two dimensions to this model. One is the end-to-end cost estimation in terms of the life cycle stages of the equipment. For example as the equipment moves into service stage of life cycle after manufacturing, the cost estimation process at bidding stage is fairly topdown based approach but for equipment already in service, the contract costing for upgrades and reducing maintenance costs a mixed approach is adopted as past historical evidence and expert judgments are available. The second dimension is the cost estimation across the entire supply network required to support the service of the equipment. This requires equal involvement of the customers and suppliers in the cost estimation approach and is found to be used in one of the contracts. Full visibility of supply chain cost drivers involving customer and suppliers is also essential in cost estimation of this type of contracts.

\section{IMPROVEMENT AREAS IN INDUSTRIAL CASE}

Several areas for improvement can be identified from this research. As can be seen from Figure 1, the risk issues identified in current cost estimating practices are mainly concerned with equipment related risks with no consideration for customer value. This remains a potential area for further research. Accuracy and joint cost modelling remains areas for further improvements in cost modelling of availability type contracts.

\subsection{Consideration of Customer-focused risks}

The current situation seems to indicate that organizations are focused on delivering the availability of their respective equipment, but finds it a challenge on several fronts in properly costing the contract. First, the change from the traditional way of doing business to availabilitytype contract has caused discomfort in terms of understanding the activities involved within the scope of the contract. While clear performance indicators relate to availability, many in the companies are aware that the performance is unachievable without the cooperation of the customer. And the impact of costing these within the contracts is not available in practice or literature. In traditional contracts, the delivery of specific activities (e.g. repair) are directly chargeable and the value to the customer is often directly attributable to what activities are rendered by the company. However, under availabilitybased contract, the performance assessed is the output of the company's collective efforts and activities, the link between customer value and the activities of the company becomes fuzzier. The defence industry's activities and structure are mostly product-centric i.e. most of the activities, solutions and models are focused around the tangible aspects of the service i.e. the equipment capabilities (that are to be maintained, repaired, overhauled or made obsolete) that contribute to the value; without much focus on the behavioural and human capabilities that also contribute towards delivering value. The focus of the organizations on tangible aspects of the service may result in the organization while estimating the costs, overlooking the effectiveness, adequacy and completeness of the service design that brings in human and equipment capabilities that deliver value to the customer. This product-centric approach to cost estimation may also limit the ability of the organization to achieve compliance and efficiency gains when delivering the service on through both equipment and human resources. On the basis of these major challenges, the companies therefore may find themselves exposed to customer-focused risks that threaten the companies' capability towards delivering service value that is replicable, consistent and scalable across future service projects. The customer-focused risk adjusted cost estimation remains an area for future improvement.

\subsection{Accuracy}

\section{Activity Profile Accuracy}

First issue is around accuracy of the estimates. Though most of the estimators interviewed answered they improved their estimate accuracy through lots and lots of evidence on what is being required, when is being required. Similarly usage is being recorded in the same way. They spent a lot of time at military bases to understand the cost drivers and actual servicing costs. But accurate visualization is absolutely essential in such costing. Industry is still unsure on predicting future activity profiles, especially under uncertain or unknown situations. The most important challenge of costing service contracts at bidding stage is estimating the activities that are new and several years in advance. There are high probabilities to always miss something and industry or literature has no proper answer on how to improve upon this.

\section{New Equipment Cost Estimates}

The issue of accuracy becomes more pronounced for new equipment service costing where no in-service data is available. All assumptions and estimates are around the equipment's operating cycle, maintenance process, but estimators don't know how it will perform in service. From the above case study examples the defence industry is found to rely more on expert knowledge and past data trying to relate it to what is known already. No simulation modelling techniques are utilised in the described case for understanding future in-service operation of the equipment. However this is reported in maintenance costing literature (Bowman and Schmee 2001).

\section{Cost Estimates for Obsolescence}

Most companies estimate mitigation cost of obsolescence based on expert knowledge and intuition on when a component is going to be obsolete. So they trust his wisdom, experience and do the costing based on the certain changes $\mathrm{s} /$ he said $\mathrm{s} /$ he has to make in the years to come. For unknown obsolescence beyond the knowledge of the expert, intelligent engineering judgments are made balancing the cost impacts of addressing such uncertainties and the affordability of MoD.

\section{Information Accuracy}

The usage data for contracts is based on MoD's maintenance line information and industry is unaware of what happens in frontline where actually the equipment is used. Hence in spite of spending lot of time in collecting past maintenance data on equipment from MoD, the 
whole picture might be totally different as availability type contracts are totally based on user's usage.

\subsection{Communication}

\section{Communication with customers}

Communication with customer is not as open and involved in most of the contracts studied. This problem is more evident in cost estimation phase of the contracts where customers take the traditional bargaining perspective of "everything costs too much". Customer has issues around different charging rates and profit level industry puts in. For some contracts which are already in service phase, requirements change a lot. Inspite of MoD's intention of making availability type contracts proactive, it remains a reactive contract as negotiating every little bit takes lot of time when the actual activity suffers delays.

\section{Communication within own organisation}

Even within own organization, several assignee levels slow things down in agreeing a cost estimate and sending that to customer. Instead of supporting the innovative things the project team wanted to include in the bid, the senior management asked their viability "Do you really want to do that?" as they were more focused on winning the contract even at lower price than usual. Senior management commitment is essential in improving contract cost estimates.

\section{Relationships with supplier}

In one of the contracts, the MoD asked the organisation and its prime supplier both to bid for the same contract. If the supplier had been brought in board earlier before the bidding process competition from own supplier could have been avoided. Joint team development with customer and suppliers is needed to gain the maximum benefits in cost estimation of such type of contracts. The repeated change in solution nature for in-service support contracts hampers supply relationships and incentivizing the suppliers.

\section{CONCLUSION}

This paper through a structured literature review and an empirical study of defence organisations identifies areas for future research in the area of availability type service support contract cost estimation. First of all, there is presently no study on cost estimation of availability type contracts in literature. Current industry practice on availability type contract cost estimation actually uses multiple cost estimation techniques at various stages of the bidding process and equipment life cycle stages. The most popular method used is analogy based cost estimation. Organisations make use of expert opinion in most contracts. The best practice identified are use of combined top-down and bottom-up costing and joint cost model build up involving customers and suppliers.

However, the challenges identified in costing of availability type service contracts are: reliability of data supplied by user or assumptions regarding equipment failure (e.g., MTBF), too much reliance on expert opinions might limit innovative thinking of uncertainties and risks, uncertainties of customer's contribution to availability performance, difficulty of not using bottom up cost estimates in every case, communication problems with the customers, prediction of maintenance activities in future (10-15 years), inability to understand cost impact of customer focused risks. From above it is clear that industry still takes a product centric focus while costing service contracts - attempting to put known numbers for a known task and relating everything back to a known thing.
This study provides opportunities for improvement in the cost estimation techniques. Firstly, companies should make people own the cost estimation process and involve people across the entire supply chain who deliver it. Secondly, risk, cost and opportunity should be estimated jointly with customers and suppliers. Thirdly, availability type service contract involves service breakdown structure that cuts through traditional departments and so service cost estimates require cross functional transformation making sure people have cross functional understanding and joint teams are most essential for effective cost estimation at early stages.

Hence this research identifies some key focal areas for further research in this area. The first is the research on the effects of customer-perceived risks in cost estimates of availability type service contracts. Then inclusion of human behavioural aspects into the cost models to make them more service focused remains a potential research area for future. Another area for future research is to use the entire supply chain cost data to improve estimate accuracy and involvement of suppliers at bidding stage. Simulation techniques applied to cost estimation models to improve the cost estimation of new equipment remains a potential area for future research. Modelling uncertainties and obsolescence costs of such contracts remains an area for further research.

\section{REFERENCES}

[1] Brax, S., 2005, A manufacturer becoming service provider - challenges and a paradox, Managing Service Quality, 15(2): 142-155.

[2] Davies, A., 2003, Are firms moving 'downstream' into high-value services?, in Tidd, J. and Hull, F.M. (Eds), Service Innovation, Series on Technology Management, Vol. 9, Imperial College Press, London, 21-34.

[3] Xu, X., Chen, J.L.-Q., Xie, S.Q., 2006, Framework of a product lifecycle costing system, Journal of Computing and Information Science in Engineering, 6: 69-77.

[4] Kirkham R. J., 2005, Re-engineering the whole life cycle costing process, Construction Management and Economics, 23: 9-14.

[5] Asiedu Y., Gu P., 1998, Product life cycle cost analysis: state of the art review, International Journal of Production Research, 36(4): 883-908.

[6] Fabrycky, W. J., Blanchard, B.S., 1991, Life-cycle cost and economic analysis, Prentice-Hall, Inc, Englewood Cliffs, NJ

[7] Christensen, P.N., Sparks, G.A., Kostuk, K.J., 2005, A method-based survey of life cycle costing pertinent to infrastructure design and renewal, Canadian Journal of Civil. Engineering, 32: 250-259.

[8] Curran R., Raghunathan S., Price M., 2004, Review of aerospace engineering cost modelling: The genetic causal approach, Progress in Aerospace Sciences, 40: 487-534.

[9] Feldman P., Shtub A., 2006, Model for cost estimation in a finite-capacity environment, International Journal of Production Research, 44(2): 305-327

[10] Roy, R., Kelvesjo, S., Forsberg, S., Rush, C., (2001), Quantitative and qualitative cost estimating for engineering design, Journal of Engineering Design, 12(2): 147-162.

[11] Harding A., Lowe, D., Emsley, M., Hickson, A., Duff, R., 1999, The role of neural networks in early stage cost estimation in the 21st century, COBRA 1999: 
The Quantitative and qualitative cost estimating for engineering design.

[12] Boussabaine, A., Kirkham, R., 2004, Whole Lifecycle Costing: Risk and risk responses. Blackwell Publishing, London, 1st Edition.

[13] Shields, M. D., Young, S. M., 1991, Managing Product Life Cycle Costs: An Organization Model, Journal of Cost Management, 5(1): 39-42.

[14] Artto, K. A., 1994, Life Cycle Cost Concepts and Methodologies, Journal of Cost Management, 8(4): 28-32.

[15] Wilkinson, S., 1996, Barriers to LCC Use in the New Zealand Construction Industry. Proceedings of the 7th International Symposium on Economic Management of Innovation, Productivity and Quality in Construction, Zagreb, 447-456.

[16] Ashworth, A., 1993, How lifecycle costs could have improved existing costing? Lifecycle costs for construction, Blackie Academic and Professional, Glasgow, UK

[17] FAA, 2002, FAA Lifecycle Cost Estimating Handbook, Investment Cost Analysis Branch, June 3 2002

[18] Stewart, R., 1995, Cost Estimators Reference Manual. Wiley-Interscience; $2^{\text {nd }}$ edition.

[19] Early, J., Wang, J., Curran, R., Price, M., Raghunathan, S., 2007, Dynamic feedback models for whole life cost prediction, Proceedings of the 7th AIAA Aviation Technology, Integration and Operations Conference, 18 - 20 September, Belfast, Northern Ireland.

[20] Nicolini, D., Tomkins, C., Holti, R. Oldman, A. Smalley, M., 2000, Can target costing and whole life costing be applied in the construction industry?: Evidence from two case studies. British Journal of Management, 11: 303-324.

[21] Jun, H.K., Kim, J.H., 2007, Life cycle cost modeling for railway vehicle. Proceedings of International Conference on electrical Machines and Systems, Oct 8-11, Seoul, Korea.

[22] Nilsson, J., Bertling, L., 2007, Maintenance management of wind power systems using condition monitoring systems - Life cycle cost analysis for two case studies. IEEE Transactions on Energy Conversion, 22(1): 223- 229.

[23] NATO Research and Technology Organization SAS028, 2003, Cost structure and Life cycle cost for military systems, Report Number: RTO-TR- 058, AC/323(SAS-028)TP/37, September 2003.

[24] Department of Defence of USA, 1993, Military standard configuration management, Report number: MIL-STD-973

[25] Komarek, J., 2001, Life Cycle Cost Simulation in Defense Planning, RTO SAS Symposium on Cost Structure and Life Cycle Cost(LCC) for Military Systems, Paris, France, 24-25 October 2001, 14/10.

[26] Griffin, J.J., 1988, Whole life cost studies: A defence management perspective, Engineering Costs and Production Economics, 14: 107-115.

[27] Jian, L., Hong-fu, Z., 2004, The predictive models of maintenance costs for a civil airplane. Proceedings of the Institution of Mechanical Engineers, 218: 347 351.

[28] Bowman, R.A., Schmee, J., 2001, Pricing and managing a maintenance contract for a fleet of aircraft engines, Simulation, 76(2): 69-77.

[29] Lamb, R.G., 1996, Determining true cost of maintenance performance can generate new profits, Pulp \& Paper, 70(10): 93-100.
[30] Beecham J, 1995, Collecting and estimating costs. In Knapp M (ed) The economic evaluation of mental health care. Arena. Ashgate Publishing Limited, London, UK, 61-82

[31] Muennig P. and Kahn K, 2002, Designing and conducting cost-effectiveness analysis in medicine and health care, Jossey-Bass. A Wiley Company, 134-157.

[32] Gyldmark M.,1995, A review of cost studies of intensive care units: problems with the cost concept, Critical Care Medicine 23(5):964-72.

[33] Beck EJ, Beecham J, Mandalia S, Griffith R, Walters MD, Boulton M, Miller, DL, 1999, What is the cost of getting the price wrong? Journal of Public Health Medicine, 21(3):311-317.

[34] Department of Health, 2005, NHS Costing Manual, Version 4.1, Internet version. UK.

[35] Luce B, Manning W, Siegel J, Lipscomb J, 1996, Estimating costs in cost effectiveness analysis. In Gold M, Siegel J, Russell L, Weinstein M (eds) cost effectiveness in health and medicine, 176-213

[36] Tanaka, T., 1993, Target costing at Toyota, Journal of Cost Management, Spring: 4-11.

[37] Miller, J.A., 1992, Target costing for the chapter 11 business, Faulkner \& Gray's Bankruptcy Law Review, 3(4): 51.

[38] Carabin H, Edmunds WJ, Gyldmark M, Beutels P, Levy-Bruhl D, Salo H, Griffiths UK, 2003, The cost of measles in industrialised countries, Vaccine 21(2730):4167-77

[39] Carabin H, Edmunds WJ, Kou U, van den Hof S, Nguyen VH, 2002, The average cost of measles cases and adverse events following vaccination in industrialised countries, BMC Public Health, 2(1):22.

[40] Ward Y. \& Graves A., 2005, Through-life management: The provision of integrated customer solutions by aerospace manufacturers. Bath Working Paper Series, http://www.bath.ac.uk/management/research/pdf/20 05-14.pdf Access date: 16/04/2008 